\title{
Reduced hyperaemia following skin trauma: evidence for an impaired microvascular response to injury in the diabetic foot
}

\author{
D. Walmsley, J.K. Wales and P.G. Wiles \\ University Department of Medicine, The General Infirmary, Leeds, UK
}

\begin{abstract}
Summary. The hyperaemic response to standard needle injury within dorsal foot skin was investigated in normal and Type 1 (insulin-dependent) diabetic subjects using laser Doppler flowmetry. The normal response was maximal within $15 \mathrm{~min}$, localised, prolonged and biphasic. In 20 normal subjects and three groups of long-duration Type 1 diabetic patients (20 without complications; 20 with laser-treated retinopathy; 15 with neuropathy and retinopathy), the median (interquartile range) peak hyperaemic responses were 1.766 $(1.220-1.970), 1.485(1.342-1.672), 0.997(0.705-1.203)$ and $1.030(0.718-1.369)$ arbitrary units, respectively. Compared to normal and uncomplicated diabetic groups, peak flow was significantly reduced in the retinopathic $(p<0.0001)$ and neu-
\end{abstract}

ropathic ( $p=0.001$ and 0.007 , respectively) groups. There was no significant difference between the normal and uncomplicated diabetic groups, nor between the retinopathic and neuropathic groups. There was no association of the hyperaemic response with blood sugar, $\mathrm{HbA}_{1 \mathrm{c}}$, or duration of diabetes. Diabetic patients who have microvascular complications, with or without neuropathy, have an associated impairment of microvascular response to mechanical injury which might predispose to infection and poor wound healing.

Key words: Injury, hyperaemia, laser Doppler flowmeter, Type 1 (insulin-dependent) diabetes mellitus, diabetic angiopathies.
The triple response to a needle prick injury to the skin consists of a local neurologically-independent vasodilatation, a more widespread but transient neurogenic flare, and a weal [1]. These vascular responses are integral parts of normal healing and may be impaired in diabetic patients [2]. Recently, using laser Doppler flowmetry [3, 4], diabetic patients have been found to have a wide range of abnormal microvascular responses $[5,6]$, including reduced hyperaemia to needle trauma in the abdominal skin [7]. Thus, a generalised abnormality of vascular response to injury may be present in diabetes, which could impair healing.

The problem of poor wound healing, infection [8] and ulceration is particularly centred on the feet of diabetic patients [9]. The aims of this study accordingly were: to characterise the hyperaemic response to a standard needle injury in the skin of the foot using laser Doppler flowmetry; to assess the local response to mechanical injury in the feet of patients with long-term Type 1 (insulin-dependent) diabetes; and to define the relationship of impairment in the response to other microvascular and neuropathic complications of diabetes.

\section{Subjects and methods}

\section{Methods}

After subjects had acclimatised lying supine in a constant temperature room at $24^{\circ} \mathrm{C}$ for $30 \mathrm{~min}$, relative cutaneous blood flow was measured by a PF1d laser Doppler flowmeter (Perimed, Stockholm, Sweden) [3]. This non-invasive technique avoids many disadvantages of other methods [7] and has been validated using synchronous dynamic capillaroscopy [10]. However, the laser Doppler signal can be affected by factors such as skin thickness, pigmentation and vessel geometry. Furthermore, blood flow in the sub-papillary plexus and arterio-venous anastomoses is measured as well as that in nutritional capillaries [11, 12]. Therefore, the laser probe was positioned on the dorsal foot, over the first two proximal metatarsal shafts, where there are no arteriovenous anastomoses [13] or callus. Thus, readings represent only capillary and subpapillary plexus flow. Other variables were limited by recruitment criteria. Local skin temperature also influences cutaneous capillary blood flow independent of the sympathetic nervous system [14-17]. Therefore, local conductive heating with a thermostaticallycontrolled probe-holder (PF2b model) was used to maintain a standard skin temperature of $32-33^{\circ} \mathrm{C}$, measured by electronic thermometer (Comark, Rustington, W. Sussex, UK). This temperature is near the top of the normal range, below that required for rapid vasodilatation ([18] and our unpublished observations) and does not interfere with neurovascular responses [19]. 


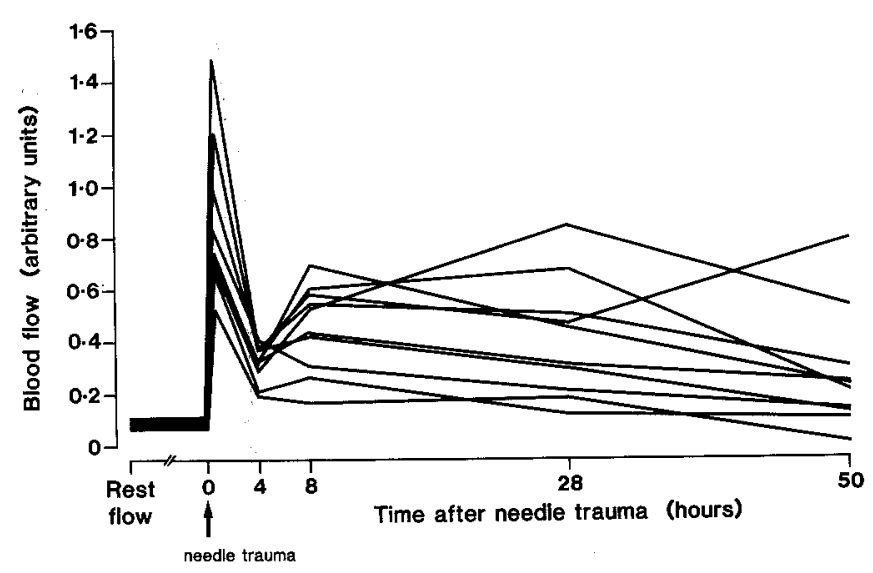

Fig. 1. The effect of standard needle injury on cutaneous blood flow measured by laser Doppler flowmetry against time. Blood flow was measured in 10 feet before, for $20 \mathrm{~min}$ after, and at $4,8,28$ and $50 \mathrm{~h}$ after injury. Control (means \pm SD) blood flows measured $35 \mathrm{~mm}$ from the injury were $0.090 \pm 0.025,0.086 \pm 0.023,0.111 \pm 0.040$, $0.101 \pm 0.039,0.132 \pm 0.072$ and $0.107 \pm 0.040$ arbitrary units, respectively. Wilcoxon's test was used to compare resting and $50 \mathrm{~h} \mathrm{blood}$ flows ( $p=0.007)$, and 4 and $8 \mathrm{~h}$ blood flow $(p=0.022)$ measured at the injury site

Mean resting blood flow was calculated from a stable 2 min period, then standard needle trauma was produced using a 25 Gauge hypodermic needle centred on the axis of the laser Doppler probe holder by a needle guard. The needle tip extended $2 \mathrm{~mm}$ below the guard and $1 \mathrm{~mm}$ below the probe holder. The peak hyperaemic response and the area under the blood flow curve during the first 15 min after injury were measured on both feet and averaged for analysis. Intra-individual coefficients of variation were $12.3 \%$ and $14.5 \%$ respectively. Neither haematomas, nor local oedema, were visible in any study.

Preliminary studies using 10 normal volunteers ( 7 male), age 24-37 years, [20] had shown that the response was maximal within $15 \mathrm{~min}$ of the injury, localised with a radius less than $5 \mathrm{~mm}$ from the injury site, prolonged up to $50 \mathrm{~h}$ and biphasic (Fig.1).

\section{Subjects}

The hyperaemic response was assessed in 20 normal volunteers and 55 long-duration Type 1 diabetic patients grouped according to their complications (Table 1): (1) normal volunteers; (2) diabetic patients without complications; (3) diabetic patients with proliferative retinopathy that had required laser therapy, but without neuropathy, and (4) diabetic patients with neuropathy and retinopathy. Thirteen subjects in group 4 had received laser therapy, one was blind and one had a marked exudative retinopathy. Nine had previously suffered from neuropathic foot ulceration.

Subjects were excluded from the study if they were over 65 years, non-caucasian, smokers, taking drugs other than insulin or had hypertension (diastolic pressure $>90 \mathrm{~mm} \mathrm{Hg}$ ), Raynaud's phenomenon, macrovascular disease (intermittent claudication or an ankle to brachial systolic pressure ratio $<1$ [21]), clinical oedema, active foot ulceration, a raised serum creatinine level or abnormal liver function tests. No patient had a blood sugar below $4 \mathrm{mmol} / \mathrm{l}$ at the start of the study, or suffered symptomatic hypoglycaemia beforehand. All studies began between 08.30 and 10.00 hours.

Type 1 diabetes was defined by ketoacidosis or an onset before 30 years of age that required insulin therapy within a few weeks of diagnosis. Retinopathy was assessed by an ophthalmologist using direct and indirect ophthalmoscopy or fundal photography. No microaneurysms, exudates or haemorrhages were seen in the uncomplicated diabetic group. The presence or absence of neuropathy was defined by the ninetieth centile of vibration perception threshold for age [22] using a biothesiometer (Biomedical Instrument Co, Newbury, Ohio, USA) on the hallux of both feet. Autonomic function was assessed by heart rate variation with deep breathing [23]. Glycaemic control was assessed from venous blood glucose and $\mathrm{HbA}_{1 \mathrm{c}}$ measured by isoelectric focussing.

The studies were approved by the hospital ethics committees and informed consent obtained from each subject.

\section{Statistical analysis}

Results are expressed as median and interquartile range. Groups were compared by the Kruskal-Wallis test. If a significant difference between the groups was found $(p<0.05)$, the two-tailed Mann Whitney $U$ test was used to define where this occurred. Rank correlation was assessed by Spearman's test.

\section{Results}

Skin temperatures at the time of peak hyperaemia and the preceding resting blood flows were comparable among the four groups (Table 2), although there was a positive correlation between the resting blood flow and peak hyperaemic flow within each diabetic subject group $\left(r_{\mathrm{s}}=0.36,0.41\right.$ and $0.47, p=0.022,0.008$ and 0.009 respectively).

There was no significant reduction of the peak hyperaemic response within $15 \mathrm{~min}$ of injury in the uncomplicated Type 1 diabetic patients when compared to the control subjects. Patients with severe retinopathy, irrespective of neuropathy, showed a highly significant reduction of the peak response compared both to the non-diabetic and to the uncomplicated diabetic groups

Table 1. Characteristics of the normal volunteers and patients with Type 1 (insulin-dependent) diabetes grouped according to complications. Results are expressed as median (interquartile range). The number of patients with persistent albustix positive proteinuria are shown. $\mathrm{E} / \mathrm{I}$ ratio $=$ the mean of (the longest R-wave interval on an electrocardiograph during expiration / shortest R-wave internal during inspiration) from six deep breaths performed in $1 \mathrm{~min}$

\begin{tabular}{|c|c|c|c|c|}
\hline & \multirow{2}{*}{$\begin{array}{l}\text { Normal } \\
\text { volunteers }\end{array}$} & \multicolumn{3}{|c|}{ Type 1 diabetic patients } \\
\hline & & $\begin{array}{l}\text { No compli- } \\
\text { cations }\end{array}$ & Retinopathy & $\begin{array}{l}\text { Neuropathy } \\
\text { and retinopathy }\end{array}$ \\
\hline $\begin{array}{l}\text { Number (male } \\
\text { female) }\end{array}$ & $9: 11$ & $15: 5$ & $12: 8$ & $9: 6$ \\
\hline Age (years) & $\begin{array}{l}44 \\
(32-55)\end{array}$ & $\begin{array}{l}43.5 \\
(39-51)\end{array}$ & $\begin{array}{l}39 \\
(33-48)\end{array}$ & $\begin{array}{l}50 \\
(39.75-56.25)\end{array}$ \\
\hline Proteinuria & 0 & 0 & 2 & 4 \\
\hline $\begin{array}{l}\text { Duration of } \\
\text { diabetes (years) }\end{array}$ & 0 & $\begin{array}{c}23.5 \\
(16-29)\end{array}$ & $\begin{array}{l}26 \\
(21-28)\end{array}$ & $\begin{array}{l}32.5 \\
(23.75-34.75)\end{array}$ \\
\hline $\begin{array}{l}\text { Blood sugar } \\
(\mathrm{mmol} / \mathrm{l})\end{array}$ & $\begin{array}{l}4.1 \\
(3.8-4.4)\end{array}$ & $\begin{array}{l}12.9 \\
(6.7-17.6)\end{array}$ & $\begin{array}{l}13.1 \\
(8.0-17.5)\end{array}$ & $\begin{array}{l}13.2 \\
(7.7-21.9)\end{array}$ \\
\hline $\mathrm{HbA}_{1 \mathrm{c}}(\%)$ & $\begin{array}{l}6.2 \\
(5.5-6.7)\end{array}$ & $\begin{array}{l}9.25 \\
(8.1-10.3)\end{array}$ & $\begin{array}{l}10.0 \\
(9.0-11.0)\end{array}$ & $\begin{array}{l}10.9 \\
(9.8-11.9)\end{array}$ \\
\hline $\begin{array}{l}\text { Mean vibration } \\
\text { perception thres- } \\
\text { hold (V) }\end{array}$ & $\begin{array}{c}7.5 \\
(5.5-8.5)\end{array}$ & $\begin{array}{l}9.0 \\
(6.5-11.0)\end{array}$ & $\begin{array}{l}10.25 \\
(8.5-12.5)\end{array}$ & $\begin{array}{l}42.0 \\
(31.0-45.5)\end{array}$ \\
\hline $\mathrm{E} / \mathrm{I}$ ratio & $\begin{array}{l}1.34 \\
(1.24-1.59)\end{array}$ & $\begin{array}{l}1.28 \\
(1.19-1.53)\end{array}$ & $\begin{array}{l}1.14 \\
(1.09-1.18)\end{array}$ & $\begin{array}{l}1.05 \\
(1.04-1.19)\end{array}$ \\
\hline
\end{tabular}


Table 2. Details of the mean resting blood flow levels, skin temperature at peak hyperaemia, and area under the curve of blood flow against time during the first $15 \mathrm{~min}$ after injury in the $\mathbf{4}$ groups. Results are expressed as median (interquartile range) and significance levels, assessed for the four groups by the Kruskal-Wallis test, are given

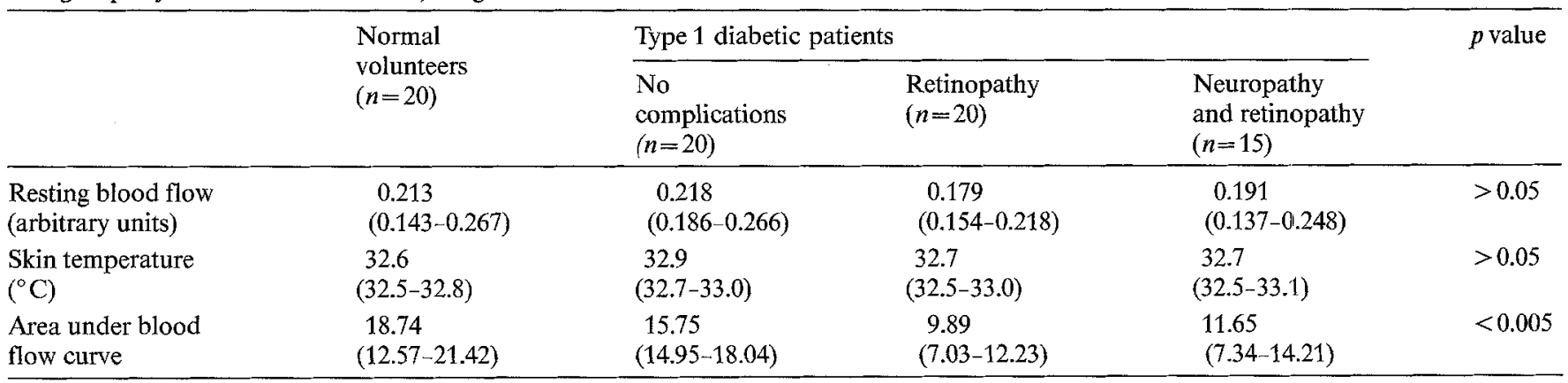

(Fig. 2). Analysis of area under the blood flow curve during 15 min after trauma (Table 2) gave the same pattern of results. There was no correlation of the hyperaemic response with blood sugar, $\mathrm{HbA}_{1 \mathrm{c}}$ or duration of diabetes.

\section{Discussion}

We have described an impairment of the hyperaemic response to mechanical injury in the feet of long-duration Type 1 diabetic subjects that is associated with other manifestations of microvascular disease. This has not been reported before and might explain the association between retinopathy and foot lesions $[24,25]$.

The hyperaemic response to cutaneous needle trauma measured by laser Doppler flowmetry represents the first (neurologically-independent) part of Lewis' triple response [1]. It is localised, has a gradual onset and a protracted course. The response is biphasic, as noted by Lewis, and the secondary hyperaemia has a similar time-course to late-phase cutaneous IgE-medi-

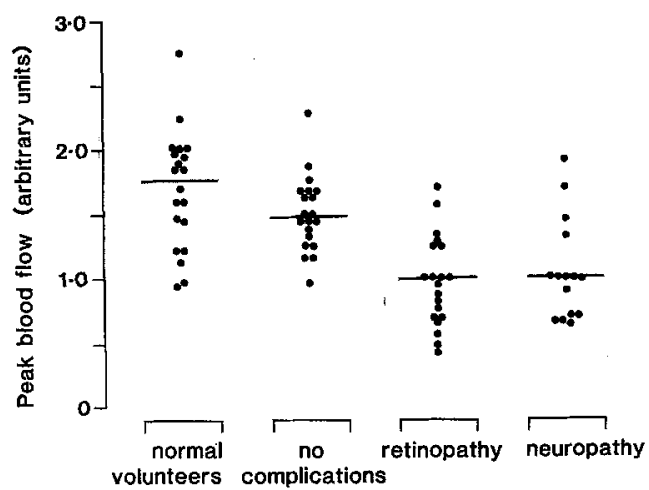

Fig. 2. Mean peak hyperaemic responses to standard needle injury measured by laser Doppler flowmetry on the dorsal skin of both feet in normal and Type 1 (insulin-dependent) diabetic subjects grouped according to their complications. Bars represent the median values. Responses were reduced in the retinopathic $(n=20, p<0.0001)$ and the neuropathic ( $n=15, p=0.001$ and 0.007 , respectively) diabetic groups compared with the normal $(n=20)$ and uncomplicated diabetic $(n=20)$ groups ated reactions [26] and the release of acute phase proteins after injury [27], suggesting that activated macrophages may be involved. The first $15 \mathrm{~min}$ of hyperaemia represents the initiation of a local complex vascular response to tissue damage. Thus, an impaired initial response is likely to indicate microvascular disease and was associated with retinopathy in these diabetic patients.

The impaired response is unlikely to be caused by altered capillary density as this was unchanged in vivo [28] and on histology [29] in diabetic patients with complications. Also, the resting blood flow levels at a standard skin temperature were similar for the four groups, although there was a correlation between resting flow and peak hyperaemia in each diabetic group. An appropriate supine non-shunt flow is therefore maintained in diabetic subjects with or without microvascular complications. The reported high capillary flow in neuropathic diabetic subjects [28] may result from temperature differences caused by increased arteriovenous shunting $[30,31]$. The effects of aging on capillary density [32] and neuropathy [22] were minimised using an age limit of 65 years. Structural vascular changes, such as acellular capillaries and pericyte degeneration [29, 33], might have reduced the response, although they have not yet been well described in relation to diabetic retinopathy.

Skin blood flow is under sympathetic control as well as responding to local temperature variations. We made no effort to abolish sympathetic tone as we were examining the response under normal conditions. The presence of sympathetic tone would undoubtedly have reduced cutaneous blood flow [17, 34] and contributed to inter-individual variations in the response. If we had abolished sympathetic tone, the group differences are likely to have been clearer because both neuropathic and retinopathic groups had reduced autonomic activity assessed by deep breathing (Table 1).

Our finding of a normal hyperaemic response to needle trauma in uncomplicated Type 1 diabetic patients is in apparent contrast to that reported by Rayman et al. [7]. However, this could be explained by some of their patients having background retinopathy and their use of a larger stimulus. Neither study showed a 
correlation between the response and short- or medium-term glycaemic control.

We have shown that microvascular complications, with or without neuropathy, are the major features associated with an impaired hyperaemic response to mechanical injury in the dorsal foot of diabetic patients. As vasodilatation and high capillary flow are themselves important stimuli for angiogenesis [35], this impaired response could contribute to the poor wound healing and infection often seen in diabetic feet.

Acknowledgements. We would like to thank Dr. A.K. Waters and Dr. D. Barnett for allowing us to study their patients, and Dr. J.A.Davies for his helpful comments on the manuscript. D. Walmsley was supported by Bayer (UK) Ltd.

\section{References}

1. Lewis $\mathrm{T}$ (1927) The blood vessels of the human skin and their responses. Shaw and Sons, London, pp 46-80

2. Starr I Jr (1930) Studies on the circulation of the feet in diabetes mellitus with and without gangrene. Am J Med Sci 180: 149-171

3. Nilsson GE, Tenland T, Öberg PA (1980) Evaluation of a laser Doppler flowmeter for the measurement of tissue blood flow. IEEE Trans Biomed Eng 27: 597-604

4. Rayman GA (1987) The laser Doppler flowmeter: clinical and physiological application. In: Tooke JE, Smaje LH (eds) Clinical investigation of the microcirculation. Martinus Nijhoff Publishing, London, pp 51-70

5. Tooke JE, Rayman G, Boolell M (1987) Blood flow abnormalities in the diabetic foot: diagnostic aid or research tool? In: Connor $\mathrm{H}$, Boulton AJM, Ward JD (eds) The Foot in Diabetes: Proceedings of the $1^{\text {st }}$ National Conference on the Diabetic Foot, Malvern, May 1986. John Wiley \& Sons, Chichester, pp 23-31

6. Parkhouse N, Le Quesne PM (1988) Impaired neurogenic vascular response in patients with diabetes and neuropathic foot lesions. $\mathrm{N}$ Engl J Med 318: 1306-1309

7. Rayman G, Williams SA, Spencer PD, Smaje LH, Wise PH, Tooke JE (1986) Impaired microvascular hyperaemic response to minor skin trauma in type 1 diabetes. Br Med J 292: 1295-1298

8. Wheat LJ (1980) Infection and diabetes mellitus. Diabetes Care 3: 187-197

9. Oakley W, Caterall RCF, Martin MM (1956) Aetiology and management of lesions of the feet in diabetes. Br Med J 2: 953-957

10. Tooke JE, Östergren J, Fagrell B (1983) Synchronous assessment of human skin microcirculation by laser Doppler flowmetry and dynamic capillaroscopy. Int J Microcirc Clin Exp 2: 277-284

11. Engelhart M, Kristensen JK (1983) Evaluation of cutaneous blood flow responses by ${ }^{133}$ xenon washout and a laser Doppler flowmeter. J Invest Dermatol 80: 12-15

12. Tenland T, Salerud EG, Nilsson GE, Öberg PÅ (1983) Spatial and temporal variations in human skin blood flow. Int $J$ Microcirc Clin Exp 3: 81-90

13. Grant RT, Bland EF (1931) Observations on arteriovenous anastomoses in human skin and in the bird's foot with special reference to cold. Heart 15:385-411

14. Hales JRS, Iriki $M$ (1975) Integrated changes in regional circulatory activity evoked by spinal cord and peripheral thermoreceptor stimulation. Brain Res 87: 267-279

15. Hales JRS, Fawcett AA, Bennett JW (1975) Differential influences of CNS and superficial body temperatures on the partition of cutaneous blood flow between capillaries and arteriovenous anastomoses. Pflügers Arch 361: 105-106

16. Hales JRS, Iriki M, Tsuchiya K, Kozawa E (1978) Thermallyinduced cutaneous sympathetic activity related to blood flow through capillaries and arteriovenous anastomoses. Pflügers Arch 375: $17-24$

17. Johnson JM, Brengelmann GL, Hales JRS, Vanhoutte PM, Wenger CB (1986) Regulation of the cutaneous circulation. Fed Proc 45: 2841-2850

18. Fagrell B, Intaglietta M (1977) The dynamics of skin microcirculation as a tool for the study of systemic diseases. Bibl Anat 16 : 231-234

19. Hassan AAK, Tooke JE (1988) Effect of changes in local skin temperature on postural vasoconstriction in man. Clin Sci 74: 201-206

20. Walmsley D, Wiles PG (1.988) Hyperaemia to skin microtrauma in the foot: a biphasic response. Clin Sci 74 [Suppl 18]: 25,91P

21. Yao ST, Hobbs JT, Irvine WT (1969) Ankle systolic pressure measurements in arterial disease affecting the lower extremities. Br J Surg 56: 676-679

22. Bloom S, Till S, Sönksen P, Smith S (1984) Use of a biothesiometer to measure individual vibration thresholds and their variation in 519 non-diabetic subjects. Br Med J 288: 1793-1795

23. Sundkvist G, Almér LO, Lilja B (1979) Respiratory influence on heart rate in diabetes mellitus. Br Med J 1: 924-925

24. Walsh CH, Soler NG, Fitzgerald MG, Malins JM (1975) Association of foot lesions with retinopathy in newly diagnosed diabetes mellitus. Lancet I: 878-880

25. Young RJ, Zhou YQ, Rodriguez E, Prescott RJ, Ewing DJ, Clarke BF (1986) Variable relationship between peripheral somatic and autonomic neuropathy in patients with different syndromes of diabetic polyneuropathy. Diabetes $35: 192-197$

26. Warner JA, Pienkowski MM, Plaut M, Norman PS, Lichtenstein LM (1986) Identification of histamine releasing factor(s) in the late phase cutaneous IgE-mediated reactions. J Immunol 136: 2583-2587

27. Stuart J, Lewis SM (1988) Monitoring the acute phase response. $\mathrm{Br}$ Med J 297: 1143-1144

28. Flynn MD, Edmonds ME, Tooke JE, Watkins PJ (1988) Direct measurement of capillary blood flow in the diabetic neuropathic foot. Diabetologia 31: 652-656

29. Malik RA, Newrick PG, Sharma AK, Jennings A, Ah-See AK, Mayhew TM, Jakubowski J, Boulton AJM, Ward JD (1989) Microangiopathy in human diabetic neuropathy: relationship between capillary abnormalities and the severity of neuropathy. Diabetologia 32: 92-102

30. Archer AG, Roberts VC, Watkins PJ (1984) Blood flow patterns in painful diabetic neuropathy. Diabetologia 27: 563-567

31. Boulton AJM, Scarpello JHB, Ward JD (1982) Venous oxygenation in the diabetic neuropathic foot: evidence of arteriovenous shunting? Diabetologia 22:6-8

32. Ryan TJ (1976) The blood vessels of the skin. J Invest Dermatol 67: $110-118$

33. Tilton RG, Faller AM, Burkhardt JK, Hoffmann PL, Kilo C, Williamson JR (1985) Pericyte degeneration and acellular capillaries are increased in the feet of human diabetic patients. Diabetologia 28: $895-900$

34. Low PA, Newmann C, Dyck PI, Fealey RD, Tuck RR (1983) Evaluation of skin vasomotor reflexes by using laser Doppler velocimetry. Mayo Clin Proc 58: 583-592

35. Hudlická O (1984) Development of microcirculation: capillary growth and adaptation. In: Renkin EM, Michel CC (eds) Handbook of physiology, Section 2, Vol IV, part 1. Williams and Wilkins, Baltimore, pp 165-216

Received: 27 February 1989

and in revised form: 8 June 1989

Dr. D. Walmsley

University Department of Medicine

The General Infirmary

Leeds LS1 3EX

UK 